\title{
An Empirical Model for Industrial Generator's Capacity Requirement Determination
}

\author{
B. O. Akinnuli ${ }^{1} \&$ T. C. Akintayo ${ }^{1}$ \\ ${ }^{1}$ School of Engineering and Engineering technology, Federal University of Technology, Akure, Ondo State, \\ Nigeria \\ Correspondence: Basil Olufemi Akinnuli, School of Engineering and Engineering technology, Federal University \\ of Technology, Akure, Ondo State, Nigeria. Tel: 234-803-465-9522. E-mail: ifembola@yahoo.com
}

Received: May 13, 2014

doi:10.5539/emr.v4n2p70
Accepted: October 17, 2015

URL: http://dx.doi.org/ emr.v4n2p70
Online Published: October 19, 2015

\begin{abstract}
In our community today, the existence of Power Holding Company of Nigeria can only help for a short period when it is available. In some areas, it is not available at all. Therefore, there is always need for generator as back up or continuous use in our industries. Determination of capacity of generator to procure is always a problem. Some company by error purchased generators that cannot carry the load of their industries. This always led to load shed either on machines or the entire facilities they have. This is due to the fact that the capacity of the generator required was not predetermined and also the expansion of the companies in the nearest future was not considered. This had contributed to the low productivity of many companies because of their inability to meet their monthly as well as yearly production targets. Hence the development of a model for the appropriate generator capacity selection for industrial installation which is empirically oriented. Developing an empirical model for this selection involves adequate understanding of electrical load distributions, variations and utilities connected to the electrical load of the generator. Parameters for industrial generator capacity were identified, mathematical model for each parameter were determined and integrated to form a unique model for decision making. The identified parameters are: capacity utilization, diversity factors, deration factor and usage type. The scenarios for computation were three based on the type of load required. This load were identified to be existing load, new and future loads. The developed models were applied using Honeywell foods (FMCG) company as case study under the first scenario. The load analysis for both the non-factory and factory load gave Summation of $531.47 \mathrm{~kW}$ with power factor of 0.8 gave a converted value of $664.34 \mathrm{kVA}$. The total variation factor gotten is 0.765 with 0.85 capacity utilization factor and diversity factor was 0.9 . Application of total variation factor gave the converted load of $664 . \mathrm{kVA}$ and new load value of $508 \mathrm{kVA}$. Using power factor of 0.8 resulted into $406 \mathrm{~kW}$ the generator considerations were derating factor of 0.75 and usage type factor (which is continuous) is 1 or $100 \%$. The final determined generator capacity for this case study using derating factor of 0.75 made the required capacity to be $677 \mathrm{kVA}$, and $542 \mathrm{~kW}$.
\end{abstract}

Keywords: empirical model, industrial generator, capacity requirement, parameters case study

\section{Introduction}

Electricity generator in industry are alternative to power supplied by the grid system which is of importance to the industrial sector. One is it's significant use gained in isolated industrial installation such as remote oil and gas installation, a new project site not yet connected to the national grid and where industrial generator has gained lengthened due to unreliable power supply from the national grid system. This could be a sources of backup in case of usage of grid power supply or out rightly powering industries via generating plants. This usage is very prominent in the Nigeria industrial sector where power supply is epileptic.

Industrial generator plays a cardinal role in the smooth operation of industrial system (plants) which is wrongly selected can adversely affect the operation, and subsequently the fortune of such a company (David, 2001). The central role generators play in the industries call for need to adequately capture the entire requirement for determining the required generator of a particular industry.

A generator, been an electro-mechanical device with additional control equipment has several factors both internal and external in it and these has to be considered (Yadav, 2009). However, the external factors often the load and its various factor play a more prominent role in determining the generator capacity requirement. 
Secondly, generator's electrical parameters and mechanical parameters are considered in determining the capacity requirement. This is so because no generator can operate beyond its name plate ratings (mechanical and electrical) (Rayput, 2006; Diesel, 2013).

The certainty of mathematical modeling makes at a unique option of modeling to be selected for decision making. Also modeling serves to simplify the study of complex system into simple and easily understandable one (Aroraectal, 2008) hence, its application to electric generator capacity requirement of this study. Rahela and Ku Ruhana (2011) modeled a worked allocation on a network of Heterogenous computers; Akinnuli and Oluwadare (2011) modeled machinery pronouncement Due-date prediction in production industries. Ogunwolue et al. (2012) modeled multi-item, multi-period dynamic capacity-constrained lot-sizing with parallel machine and fuzzy demand, Akinnuli et al. (2012) also modeled job-shop flows time and due-date prediction, Kareem and Aderoba (2012) developed a hauristics model for simplifying a multi-channel queing system, modeling analysis of the wire-drawing operation using the weigheted-residual finite element method was carried out by Oladende and Akpobi (2012). These are current model developed but non is yet to address the problem of electric generator's capacity required in an industrial set up. Hence the development of a model based on historical information from the electrification plan of the industry before or after construction. This will strongly assist the appropriate decision making before procurement and installation of electric generators required.

\section{Methodology}

Parameters required for industrial electric generator's capacity were identified and mathematical models were integrated to form a unique model as an entity. The developed model was tested on the case study selected to evaluate it's performance.

Model Parameters and Explanation: the considered factors are: plant or load structure, load consideration, load variation and generator consideration.

Load Structure: this entails looking at all load centres, consider their dependency or separation thus help to be able to determine if a single or multiple set of generators that will be needed. The basic consideration is the number of independent separated load centre and their ratio to the total load. Thus is shown in equation 2.1

$$
C=c_{1}+c_{2}+c_{3}+\ldots+c_{n}
$$

Where $\boldsymbol{C}=$ Total load

$\boldsymbol{c}_{\boldsymbol{n}}=$ Various center/Separation of load.

Load consideration: loads are the most important considerations when considering generator capacity rating. The loads are rated either in house power, Kilo voltage, Amperes, Kilowatts or Power factor or as a combination of any of these. The three basic loads normally considered are the: (i) Existing load (ii) New load and (iii) future load. These are represented as: $\mathrm{X}, \mathrm{Y}, \mathrm{Z}$ respectively. The computation are of three scenarios which are computation for $\mathrm{X}, \mathrm{X}+\mathrm{Y}$ or $\mathrm{X}+\mathrm{Y}+\mathrm{Z}$. the situation at hand will determine the scenario to be adopted.

Load Variation: in industrial installations, the supposedly total loads are not attached (utilized) due to the fact that all installations do not work simultaneous are capacity utilization (A) and diversity factor (B). the load variation is the product of capacity utilization and diversity factor as shown in equation 2.2

$$
\mathrm{Lv}=\mathrm{AB}
$$

It should be noted that of all the three possible load types only existing load are considered here as the other two are not applicable.

Generator Considerations: though the model has no leverage over the name plate of generator, factors applied to generator also affect the final model result. These factors required in the model development are represented as derating factor D and usage type $\mathrm{E}$ (either continuous or stand-by). This is written as

$$
\mathrm{Ge}=\mathrm{DE}
$$

Model Development: the above factions were consideration for the model development and steps were as follows:

(A) The total loads: these are the existing load " $\mathrm{X}$ " (factory and non-factory loads) and New load "Y" (loads not yet connected to the system but have been procured) and the future planned load " $Z$ ".

The total load is the value for " $\mathrm{X}$ " or combinations of $\mathrm{X}, \mathrm{Y}$ and $\mathrm{Z}$ this resulted into three scenarios with different equations.

(a) First scenario is when only the existing load (X) is considered

$$
\mathrm{T}_{\mathrm{L}}=\mathrm{X}
$$


(b) Second scenario is consideration for the existing load (X) and the new load $\mathrm{Y}$

The total load then is

$$
\mathrm{T}_{\mathrm{L}}=\mathrm{X}+\mathrm{Y}
$$

Third scenario is when consideration is given to all the three loads that is the existing, new and the future loads $\mathrm{X}$, $\mathrm{Y}$, and $\mathrm{Z}$

The total load then becomes

$$
\mathrm{T}_{\mathrm{L}}=\mathrm{X}+\mathrm{Y}+\mathrm{Z}
$$

After the selection of the needed scenario, then comes (B)

(B) Application of variation factors to get new load required: this also led to equations 2.5(a, b, and c) based on the scenario selected. The variation factors has been defined in equations 2.2 as $\mathrm{L}_{\mathrm{v}}=\mathrm{AB}$

Therefore the equation for the three scenarios becomes

$$
\begin{gathered}
\mathrm{L}_{\mathrm{n}}=\mathrm{XL}_{\mathrm{v}}(\text { for first scenario) } \\
\mathrm{L}_{\mathrm{n}}=(\mathrm{X}+\mathrm{Y}) \mathrm{L}_{\mathrm{v}}(\text { for second scenario) } \\
\mathrm{Ln}=(\mathrm{X}+\mathrm{Y}+\mathrm{Z}) \mathrm{Lv} \text { (for third scenario) }
\end{gathered}
$$

After the computation of the new load Ln then comes $(\boldsymbol{C})$

(C) Application of the load centres consideration factor: this is shown in equation 2.1

$$
\mathrm{C}=\mathrm{C}_{1}+\mathrm{C}_{2}+\mathrm{C}_{3}+------------\mathrm{C}_{\mathrm{n}}=
$$

Then the total load " $\mathrm{T}_{\mathrm{L}}$ " for three scenarios above becomes:

$$
\begin{aligned}
& =(\text { first scenario }) \\
= & (\text { Second scenario }) \\
= & (\mathrm{X}+\mathrm{Y}+\mathrm{Z}) \text { (third scenario })
\end{aligned}
$$

After the total load has been defined, then the generator considerations which is the product of the derating factor " $D$ " and usage type "E" was used as the denominator to the calculated total load $T_{L 1}, T_{L 2}, T_{L 3}$ these are shown in (d).

(D) Application of generator consideration factors: this helps to determine the required generator capacity needed for the industry based on the selected scenario. Generator consideration $\mathrm{Gc}=\mathrm{DE}$ as in equation 2.3.

Therefore the generator capacity required will be

$$
\begin{aligned}
\mathrm{T}_{\mathrm{L} 1} & =\left(\mathrm{XL}_{\mathrm{V}}\right) / \mathrm{GC} \\
\mathrm{T}_{\mathrm{L} 2} & =(\mathrm{X}+\mathrm{Y}) \mathrm{L}_{\mathrm{v}} / \mathrm{GC} \\
\mathrm{T}_{\mathrm{L} 3} & =(\mathrm{X}+\mathrm{Y}+\mathrm{Z}) / \mathrm{GC}
\end{aligned}
$$

\section{Used Conversions:}

$1 \mathrm{HP}=750 \mathrm{~W}$

$1.5 \mathrm{HP}=1.5 \times 750=1125 \mathrm{~W}$

$2 \mathrm{HP}=2 \times 750=1500 \mathrm{~W}$

$\mathrm{W}=\mathrm{I} \times \mathrm{V}$, Value of current $\times 240 \mathrm{~V}=$ Rate Watt

$\mathrm{kW}=0.8 \times \mathrm{kVA}$. Power factor $=0.8, \mathrm{HP}=$ Horse Power; Current $=\mathrm{I}$ and $\mathrm{V}=$ Voltage

Electrical Units and formula Used

$$
\begin{aligned}
& 1 \mathrm{HP}=750 \mathrm{~W} \\
& \mathrm{VA} \cos \varnothing=\mathrm{W} \\
& (\mathrm{VA})^{2}=(\mathrm{VA} \cos \varnothing)^{2}+(\mathrm{VA} \sin \varnothing)^{2} \\
& \text { P.f. }=\cos \varnothing \\
& \text { P.f. }=\text { W/VA (Richard C. Bailie, 1999) }
\end{aligned}
$$


UNITS:

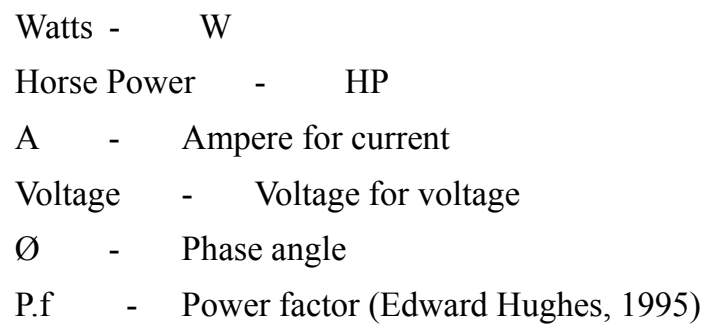

\section{Model Application}

\section{Case Study for Model Application}

Honeywell foods (EMCG) company located at Mobolaji Johnson Avenue, Alausa Lagos was considered as case study for the application of this developed models. Each model starts with the analysis of the loads involved in the industrial installation.

In this case study the available load for consideration is the existing " $X$ " load. The new load "Y" and the future load "Z" are not required.

The non-factory loads in this case study are the: guest house load, administrative block load, sale building block load and quality assurance load. While the factory loads are loads that are directly related to the production on the factory floor and these are: utility load and noodles factory load.

\section{Load Estimate for Non-factory and Factory loads}

Load Estimate for Non-factory loads: the new load "Y" $=0$, and the feature load " $Z$ " $=0$,

From these, we see that new load and future load does not exist and only existing load is to be considered in the industrial installation of this case study.

The existing load was considered and analysed from two broad grouping. This is needed should there be need to be separately powered.

i. Non-factory loads.

ii. Factory loads.

They are further sub-divided as below:

i. Non-factory loads: these are loads that are not directly related to production on the factory floor.

They are further sub-divided into: Guest house load; Administration block load; Sales building block load and Quality Assurance load.

ii. Factory loads: these are loads that are directly related to production on the factory floor. They are further sub-divided into: Utility load; and Noodles factory load.

\section{NON-FACTORY LOAD}

\section{A. Guest house load:}

This comprises of 20nos of 3 bedroom flat, 2nos of 2 bedroom flat, 2 nos 1 bedroom flat and 6nos of 1 room apartment.

Table 1. Guest house load determination

\begin{tabular}{llll}
\hline DESCRIPTION & RATING & NO OF UNITS & W/KW(WATTS) \\
\hline GUEST HOUSE LOAD & & & \\
Fluorescent bulb & $36 \mathrm{~W}$ & 26 & $26 * 36=936 \mathrm{~W}$ \\
Bulb & $60 \mathrm{~W}$ & 15 & $60 * 15=900 \mathrm{~W}$ \\
Air conditioning units (1.5HP) & $1125 \mathrm{~W}$ & 5 & $5 * 1125=5625 \mathrm{~W}$ \\
Air conditioning units (2HP) & $1500 \mathrm{~W}$ & 8 & $8 * 1500=12000 \mathrm{~W}$ \\
Television set & $54 \mathrm{~W}$ & 7 & $7 * 54=378 \mathrm{~W}$ \\
Refrigerators (0.3A) & $72 \mathrm{~W}$ & 7 & $7 * 72=504 \mathrm{~W}$ \\
\hline
\end{tabular}




$\begin{array}{llll}\text { Electric cookers } & 1200 \mathrm{~W} & 5 & 5 * 1200=6000 \mathrm{~W} \\ \text { Microwave oven } & 1000 \mathrm{~W} & 4 & 4 * 1000=4000 \mathrm{~W} \\ & & & \text { TOTAL }=30343 \mathrm{~W} / 30.343 \mathrm{KW}\end{array}$

B. Administrative block load: This comprises of the ground and $1^{\text {st }}$ floor for the Administrative offices, Financial Account office, Management Account office, Marketing office, Information Technology Office, Meeting room, Conference room, Training room, Rest room and Reception.

Table 2. Administrative block load determination

\begin{tabular}{lccl}
\hline DESCRIPTION & RATING & NO OF UNITS & W/KW(WATTS) \\
\hline ADMINISTRATIVE BLOCK LOAD (GROUND FLOOR) & \\
Fluorescent bulb & $36 \mathrm{~W}$ & 28 & $28 * 36=1008 \mathrm{~W}$ \\
Photocopier (6.5A) & $1560 \mathrm{~W}$ & 1 & $1 * 1560=1560 \mathrm{~W}$ \\
Air conditioning units (1.5HP) & $1125 \mathrm{~W}$ & 6 & $6 * 1125=6750 \mathrm{~W}$ \\
Air conditioning units (2HP) & $1500 \mathrm{~W}$ & 6 & $6 * 1500=9000 \mathrm{~W}$ \\
Hand drier & $2400 \mathrm{~W}$ & 4 & $4 * 2400=9600 \mathrm{~W}$ \\
Refrigerators (5A) & $1200 \mathrm{~W}$ & 2 & $2 * 1200=2400 \mathrm{~W}$ \\
Computer system (1.8A) & $432 \mathrm{~W}$ & 12 & $12 * 432=5184 \mathrm{~W}$ \\
ADMINISTRATIVE BLOCK LOAD (1st FLOOR) & & \\
Air conditioning units (1.5HP) & $1125 \mathrm{~W}$ & 10 & $10 * 1125=11250 \mathrm{~W}$ \\
Fluorescent bulb & $36 \mathrm{~W}$ & 30 & $30 * 36=1080 \mathrm{~W}$ \\
Refrigerators (7A) & $1680 \mathrm{~W}$ & 2 & $2 * 1680=3360 \mathrm{~W}$ \\
Computer system (1.6A) & $384 \mathrm{~W}$ & 8 & $8 * 384=3072 \mathrm{~W}$ \\
Computer systems(1.8A) & $432 \mathrm{~W}$ & 5 & $5 * 432=2160 \mathrm{~W}$ \\
UPS (5KVA) & $4000 \mathrm{~W}$ & 1 & $1 * 4000=4000 \mathrm{~W}$ \\
& & & TOTAL=24922W/24.922KW \\
\hline
\end{tabular}

\section{Sales building block load}

Table 3. Sale block load determination

\begin{tabular}{llll}
\hline DESCRIPTION & RATING & NO OF UNITS & W/KW(WATTS) \\
\hline SALES BUILDING BLOCK LOAD & & & \\
Fluorescent bulb & $36 \mathrm{~W}$ & 22 & $22 * 36=792 \mathrm{~W}$ \\
Photocopier & $1200 \mathrm{~W}$ & 1 & $1 * 1200=1200 \mathrm{~W}$ \\
Computer system (1.6A) & $384 \mathrm{~W}$ & 8 & $8 * 384=3072 \mathrm{~W}$ \\
Computer systems(1.8A) & $432 \mathrm{~W}$ & 7 & $7 * 432=3024 \mathrm{~W}$ \\
Air conditioning units (2HP) & $1500 \mathrm{~W}$ & 12 & $12 * 1500=18000 \mathrm{~W}$ \\
Printer (1.6A) & $384 \mathrm{~W}$ & 4 & $4 * 384=1536 \mathrm{~W}$ \\
& & & TOTAL $=27624 \mathrm{~W} / 27.624 \mathrm{KW}$ \\
\hline
\end{tabular}




\section{Quality assurance load}

Table 4. Quality assurance load determination

\begin{tabular}{llll}
\hline DESCRIPTION & RATING & NO OF UNITS & W/KW(WATTS) \\
\hline & QUALITY ASSURANCE LOAD & \\
Incubator/oven (1.36KVA) & 1088 & 3 & $3264 \mathrm{~W}$ \\
Incubator & $750 \mathrm{~W}$ & 1 & $750 \mathrm{~W}$ \\
Incubator & $3600 \mathrm{~W}$ & 1 & $3600 \mathrm{~W}$ \\
Incubator & $2500 \mathrm{~W}$ & 3 & $7500 \mathrm{~W}$ \\
Incubator & $2400 \mathrm{~W}$ & 2 & $4800 \mathrm{~W}$ \\
SOX tech. control & $1200 \mathrm{~W}$ & 1 & $1200 \mathrm{~W}$ \\
UPS & $2700 \mathrm{~W}$ & 1 & $2700 \mathrm{~W}$ \\
Analyzer (1.5A) & $360 \mathrm{~W}$ & 1 & $360 \mathrm{~W}$ \\
Petting instrument & $60 \mathrm{~W}$ & 1 & $60 \mathrm{~W}$ \\
$\mathbf{4}$ feet fluorescent & $36 \mathrm{~W}$ & 18 & $648 \mathrm{~W}$ \\
& & & TOTAL $=24882 \mathrm{~W} / 24.882 \mathrm{KW}$
\end{tabular}

The summations of the for the non-factory building are the sum of results in tables 3.1, 3.2, 3.3, 3.4 respectively $(30.343+24.922+27.624+24.882) \mathrm{kW}=107.771 \mathrm{~kW}$

Total non factory load is $107.771 \mathrm{~kW}$

\section{Factory Load}

The factory loads are hereby computed as stated below.

E. Utility unit load

Table 5. Utility unit load determination

\begin{tabular}{llll}
\hline DESCRIPTION & RATING & NO OF UNITS & W/KW(WATTS) \\
\hline UTILITY UNIT LOAD & & & \\
Vertical pump & $5500 \mathrm{~W}$ & 3 & $16500 \mathrm{~W}$ \\
Burner electric motor & $4500 \mathrm{~W}$ & 3 & $13500 \mathrm{~W}$ \\
Water pump & $5500 \mathrm{~W}$ & 5 & $27500 \mathrm{~W}$ \\
Water pump & $4500 \mathrm{~W}$ & 7 & $31500 \mathrm{~W}$ \\
Diesel pump & $3000 \mathrm{~W}$ & 5 & $15000 \mathrm{~W}$ \\
Diesel pump & $4000 \mathrm{~W}$ & 3 & $12000 \mathrm{~W}$ \\
& & & TOTAL $=116000 \mathrm{~W} / 116 \mathrm{KW}$ \\
\hline
\end{tabular}




\section{F. Noodles factory}

Table 6. Noodle factory load determination

\begin{tabular}{llll}
\hline DESCRIPTION & RATING & NO OF UNITS & W/KW(WATTS) \\
\hline & NOODLES FACTORY & \\
Electric motor & $11000 \mathrm{~W}$ & 8 & $88000 \mathrm{~W}$ \\
Electric motor & $22000 \mathrm{~W}$ & 1 & $22000 \mathrm{~W}$ \\
Electric motor & $7500 \mathrm{~W}$ & 7 & $52500 \mathrm{~W}$ \\
Electric motor & $4000 \mathrm{~W}$ & 6 & $24000 \mathrm{~W}$ \\
Compressor & $30000 \mathrm{~W}$ & 1 & $30000 \mathrm{~W}$ \\
Exhaust fan (10Hp) & $7500 \mathrm{~W}$ & 4 & $30000 \mathrm{~W}$ \\
Cooling fan (12A) & $2880 \mathrm{~W}$ & 3 & $8640 \mathrm{~W}$ \\
Conveyor motor & $1500 \mathrm{~W}$ & 12 & $18000 \mathrm{~W}$ \\
Packaging machine (16A) & $3840 \mathrm{~W}$ & 9 & $34560 \mathrm{~W}$ \\
& & & TOTAL $=307700 \mathrm{~W} / 307.7 \mathrm{KW}$ \\
\hline
\end{tabular}

Total factory load is $116.00+307.7=423.7 \mathrm{~kW}$

Since the generator is rated in $\mathrm{kVA}$, we have to sum up the load and convert back to kVA.

\section{Summary of flow chart}

In Figure 1, is a summary of the derived flow chart of the various stages involved in determining the final generator capacity requirement of the industrial installation case study. Also included are brief sources of values used for the model calculation. 


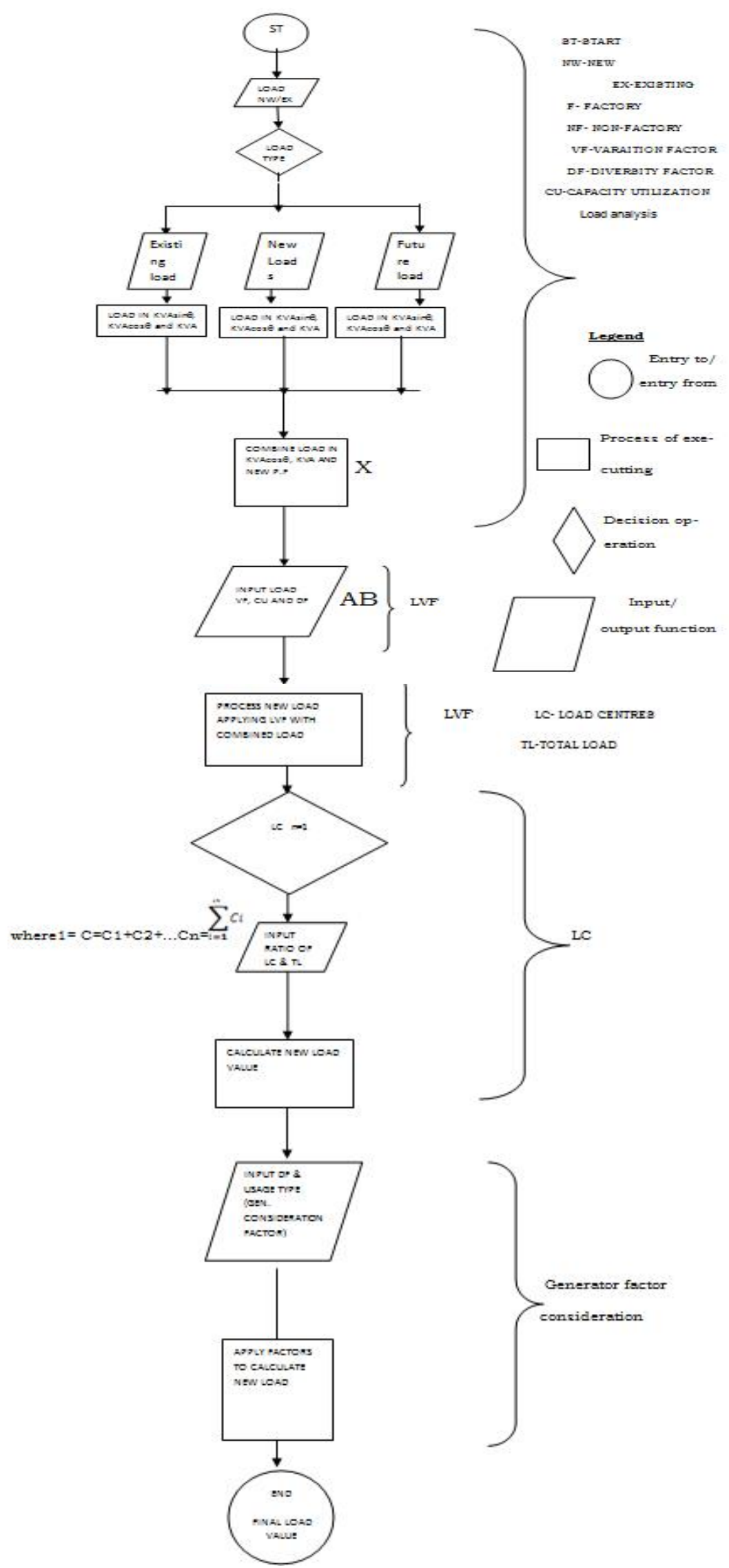

Figure 1. Procedure for generator's capacity determination 


\section{Results of Computations}

The computations are for the load analysis load Variation factors, plant load centres, generator considerations and generator's capacity determination.

\section{a. Load Analysis}

Summation of the two load centres=Non-factory load+factory load $(30.343+24.922+27.624+24.882)+(116.000+307.700)=531.471 \mathrm{~kW}$

Conversion from watt to $\mathrm{kVA}: \frac{531.471}{0.8}=664.338 \mathrm{kVA}=664.34 \mathrm{kVA}$

Total $\mathrm{kVA}=664.34 \mathrm{kVA}$

$\mathrm{kVA} \cos \theta=531.47 \mathrm{~kW}$

$\mathrm{P} . \mathrm{F}=0.8=\cos \theta$

The Power factor is derived from name plate parameters of the various loads.

\section{b. Load Variation Factors}

A $=$ Capacity Utilization $=0.85$

$\mathrm{B}=$ Diversity factor $=0.9$

Total variation factor $=0.9 \times 0.85=0.765$

Applying variation factor to total load, our new load value becomes

$\mathrm{kVA}=664.34 \mathrm{kVA} \times 0.765=508 \mathrm{kVA}$

$\mathrm{kW}=406 \mathrm{~kW}$

P.F $=0.8$

\section{c. Plant Load Centres}

Based on the existing load installation, all loads are powered from a same source; hence only one generator will be used. This translates to just a single load centre.

\section{d. Generator Considerations}

Derating (SAFETY) factor $=0.75$

Usage type factor $\longrightarrow$ Continuous use

Usage type factor $\longrightarrow 100 \%$ of the name plate

\section{e. Final Generator Capacity Etermination/Selection}

Generating capacity=New load capacity/Derating factor $\mathrm{x}$ Usage type factor

$\mathrm{kVA}=\frac{508}{0.75 \times 1}=677 \mathrm{kVA}=\mathrm{P} . \mathrm{F}=0.8$

$\mathrm{kW}=\frac{406}{0.75 \times 1}=542 \mathrm{~kW}$

Therefore, for the load considered been $664.34 \mathrm{kVA}$; a generator of $677 \mathrm{kVA}$ is ideal.

\section{Conclusion and Recommendation}

This study has identified the parameters required for generation capacity as: capacity utilization diversity factor deration factor and usage type. The models required were developed and well integrated. These developed models hasit's three scenario for selection before computation these scenario are: (i) when the directing load " $\mathrm{X}$ " only is required, (ii) when the combination of existing and new loads $(\mathrm{X}+\mathrm{Y})$ are required and the third scenario is when the existing news and third scenario is when the existing new and future loads $(\mathrm{X}+\mathrm{Y}+\mathrm{Z})$ are required. The developed models were manually applied taken Honeywell foods (FMCG) company as case study. This case study has only existing, load therefore scenario 1 (exsiting load "X") was used with two centres only which are non-factory load and factory load. 
The load analysis for both the non-factory and factory and factory loads gave summation of $531.47 \mathrm{~kW}$ which was converted using power factor of 0.8 to get a conversion value of $664.34 \mathrm{kVA}$.

The variation factors gotten is 0.765 using capacity utilization of 0.85 and diversity factor of 0.9 . when this variation factor was applied to the new load of $664.34 \mathrm{kVA}$ it gave new load of $508 \mathrm{kVA}$ using power factor of 0.8 resulted into $406 \mathrm{~kW}$.

The plant load centre one all loads are power from a source which translated is single load centre.

The generator considerations are derating factor of 0.75 usage type factor (which continuous use) is $100 \%$.

The determined final generator capacity as $664.34 \mathrm{kVA}$ therefore a generator of $677 \mathrm{kVA}$.

This model is highly recommended for small, medium and large scale industries that generator procurement affects their production. This model will assist in selecting the appropriate capacity that will serve industry industry conveniently.

\section{Acknowledgement}

I have to appreciate my student Adekunle, O. M. for his time committed to this research in area of data collection and processing.

\section{Reference}

Akinnuli, B. O., \& Oluwadare, S. A. (2011). Computer-Aided system for modeling machinery procurement due Date prediction in production industries. Journal of Information and Communication Technology, 10, 99-115.

Akinnuli, B. O., Oluwadare, S. A., \& Aderoba, A. A. (2012). A computer-Aided System for Job-Shop Flows Tune and Due-Date Prediction. Advances in Materials Research, 367, 639-646. http://dx.doi.org/10.4028/www.scientific.net/AMR.367.639

Arora, S. C., Domkundwar, S., \& Domkundwar A. V. (2008). A course in Power Plant Engineering (5th ed.). DhampetRai and Co. Ltd. NaiSarak, Delhi.

David, D. (2001). Power Plants learn to Reuse, Recycle. Power, 145(5), 45-54.

Diesel. (2013). Service and Supply. Retrieved from http://www.dieselservice and supply.com

Kareem, B., \& Aderoba, A. A. (2012). Development of a Haristes model for simplifying a Mult-Channel queuing $\begin{array}{llll}\text { System. } & \text { Advance }\end{array}$ http://dx.doi.org/10.4028/www.scientific.net/AMR.367.647

Ogunwole, L., Alli, O. A., Onyedikan, C., \& Sosimi, A. A. (2012). Multi-item Multe-Period Dynamic capacity Constrained Lot-Sizing Model with Parallel Mechanize and fizzy Demand. Advance materials Research, 367, 627-638. http://dx.doi.org/10.4028/www.scientific.net/AMR.367.627

Oladehinde, M. H., \& Akposi, J. A. (2012). Modelling Analysis of the wire-Drawing Operation Using the Heighted-Residual finite Element Method. Advance Materials Research, 367, 677-684. http://dx.doi.org/10.4028/www.scientific.net/AMR.367.677

Rahala, R., \& KuRuana, K. (2011). Optimization Workload Allocation in a Network of Heterogenous Computers. Journal of information, 10.

Rajput, R. K. (2006). Thermal Engineering (6th ed.). New Delhi: Haxmi Publications.

Yadav, R. (2009). Steam and Gas Turbine and Power Plant Engineering (7th ed.). India: Central publishing House Allahabad.

\section{Copyrights}

Copyright for this article is retained by the author(s), with first publication rights granted to the journal.

This is an open-access article distributed under the terms and conditions of the Creative Commons Attribution license (http://creativecommons.org/licenses/by/3.0/). 